Research Article

\title{
Nanographene-Based Saturable Absorbers for Ultrafast Fiber Lasers
}

\author{
Hsin-Hui Kuo and Shuo-Fu Hong \\ Department of Electrical Engineering, National University of Kaohsiung, Kaohsiung 81148, Taiwan \\ Correspondence should be addressed to Hsin-Hui Kuo; hhkuo@nuk.edu.tw
}

Received 10 February 2014; Accepted 16 February 2014; Published 20 March 2014

Academic Editor: Chien-Jung Huang

Copyright (C) 2014 H.-H. Kuo and S.-F. Hong. This is an open access article distributed under the Creative Commons Attribution License, which permits unrestricted use, distribution, and reproduction in any medium, provided the original work is properly cited.

\begin{abstract}
The generation of femtosecond pulse laser in the erbium-doped fiber laser system is presented by integrating of the nanographenebased saturable absorbers (SAs). A simplified method of dispersed nanographene-based SAs side-polished fiber device with controllable polished length and depth was also developed. The dependence of geometry of a graphene-deposited side-polished fiber device on optical nonlinear characteristics and on the performance of the MLFL was screened. We found that the $10 \mathrm{~mm}$ polished length with $1.68 \mathrm{~dB}$ insertion loss had the highest modulation depth (MD) of $1.2 \%$. A stable MLFL with graphene-based SAs employing the optimized side-polished fiber device showed a pulse width, a $3 \mathrm{~dB}$ bandwidth, a time-bandwidth product (TBP), a repetition rate, and pulse energy of $523 \mathrm{fs}, 5.4 \mathrm{~nm}, 0.347,16.7 \mathrm{MHz}$, and $0.18 \mathrm{~nJ}$, respectively, at fundamental soliton-like operation. The femtosecond pulse laser is achieved by evanescent field coupling through graphene-deposited side-polished fiber devices in the laser cavity. This study demonstrates that the polished depth is the key fabrication geometric parameter affecting the overall optical performance and better results exist within the certain polished range.
\end{abstract}

\section{Introduction}

Ultrafast lasers are interesting to researchers in diverse fields including ultrafast spectroscopy, optical coherence tomography, frequency comb generation, and material processing $[1,2]$. Mode locking is one of the techniques generating optical pulses from picosecond to femtosecond regime and a nonlinear optical element is used for producing sideband coupling to transform a continuous-wave laser into a train of optical ultrashort pulses [3-5]. The main features of a nonlinear element characterize broadband nonlinear loss modulation with fast response time and easy integration into the laser system. In passive mode locking, a semiconductor saturable absorber mirror (SESAM) was widely used [6]. However, a SESAM usually has drawbacks of cost-ineffective and time-consuming fabrication process. Recent studies have indicated that nanomaterials such as single-wall carbon nanotube (SWCNT) and graphene can be alternative media for a SA $[7,8]$. The nonlinear optical applications of CNT and graphene are well documented [9]. The first passively mode-locked fiber laser (MLFL) based on
SWCNT-SA was reported in 2003 [10]. However, in spite of the high nonlinearity of CNTs, they still have some inherent difficulties including aggregation, difficult alignment, and variable diameters for energy band gap design. Recently, it was reported that graphene has significant advantages with an ultrafast relaxation time and a wide spectral operation range due to its zero-gap linear band structure [11, 12]. Graphenebased SAs were recently reported for passively mode-locked lasers $[13,14]$ in the generation of femtosecond-scaled pulses $[15,16]$. The interaction between SAs and the signal light can be directional transmission or evanescent field coupling [9]. To avoid the thermal damage induced by the optical power, the evanescent field interaction is adopted through a sidepolished fiber or tapered fiber devices [17-19]. In addition, nonlinear effect can be controlled through the interaction length adjustment and the polished depth. The whole optical system is an all-fiber configuration.

In this study, the optical properties of mica-dispersed graphene-deposited side-polished fiber devices and the performance of a MLFL output are demonstrated. We report the effects of different polished lengths and polished depths 


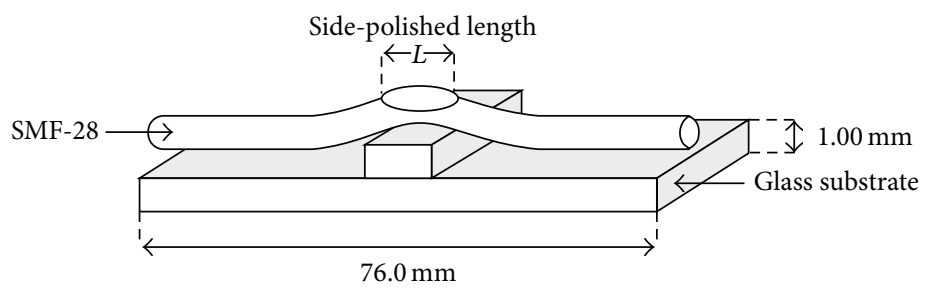

(a)

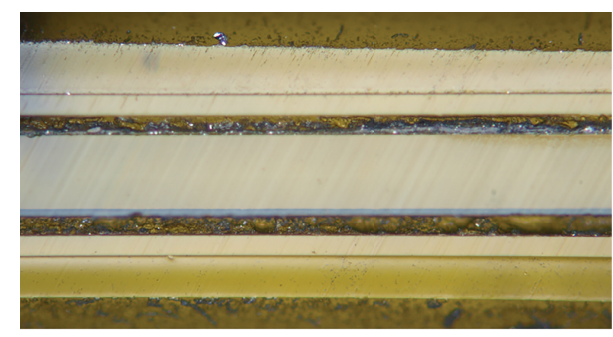

(b)

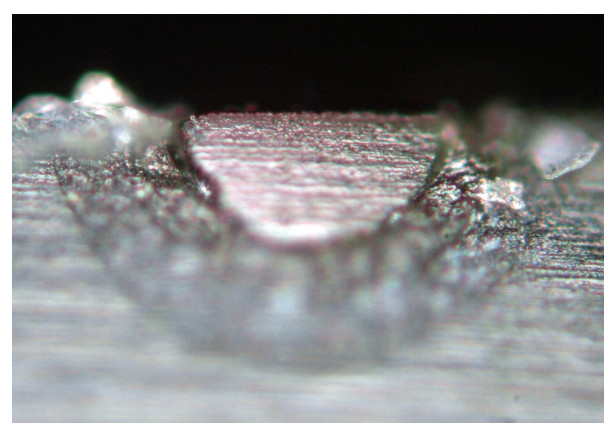

(c)

FIGURE 1: The fabrication of a side-polished fiber device. (a) The setup of the mounting, (b) the microscope image of the polished surface, and (c) the microscope image of the cross section of a side-polished fiber.

on the optical nonlinearities and on the MLFL outputs. It was found that the $10 \mathrm{~mm}$ polished length with $1.68 \mathrm{~dB}$ loss had the highest modulation depth (MD) of $1.2 \%$ in our experiments. A stable MLFL with graphene-based SAs employing the optimized side-polished fiber device showed a pulse width of $523 \mathrm{fs}$, a $3 \mathrm{~dB}$ bandwidth of $5.4 \mathrm{~nm}$, and a time-bandwidth product of 0.347 . This study of the graphenedeposited side-polished fiber device with controllable polished length and depth could provide an effective approach for the femtosecond pulse generation in the fiber laser and the polished depth of a side-polished fiber device has the stronger effect on the optical nonlinearities and the laser performance.

\section{Experimental Details}

The nanographene-deposited side-polished fiber device functions with the evanescent field interaction between the graphene-based SAs and the propagating light. We designed an easy method to make a side-polished fiber and the polished length and depth can be well controlled. A side-polished fiber was prepared by mounting a SMF28 with some curvature on stacked glass-substrates as shown in Figure 1(a). The polished length was adjusted by the length $L$ of the top glass. The fiber together with the substrates was polished by the polisher (ULTRATEC YM-380WP) with four different grain-size diamond films of $9,6,1$, and $0.1 \mu \mathrm{m}$ in sequence to ensure the noncracked and smoothly polished surface as shown in Figure 1(b). Figure 1(c) shows the cross section of the side-polished fiber. During the polishing process, the insertion loss (IL) was continuously monitored and IL indicates the polished depth $D$, the distance from the outer cladding to the polished surface. The losses of $1 \sim 3 \mathrm{~dB}$ in air were fabricated. To verify the correlation between the

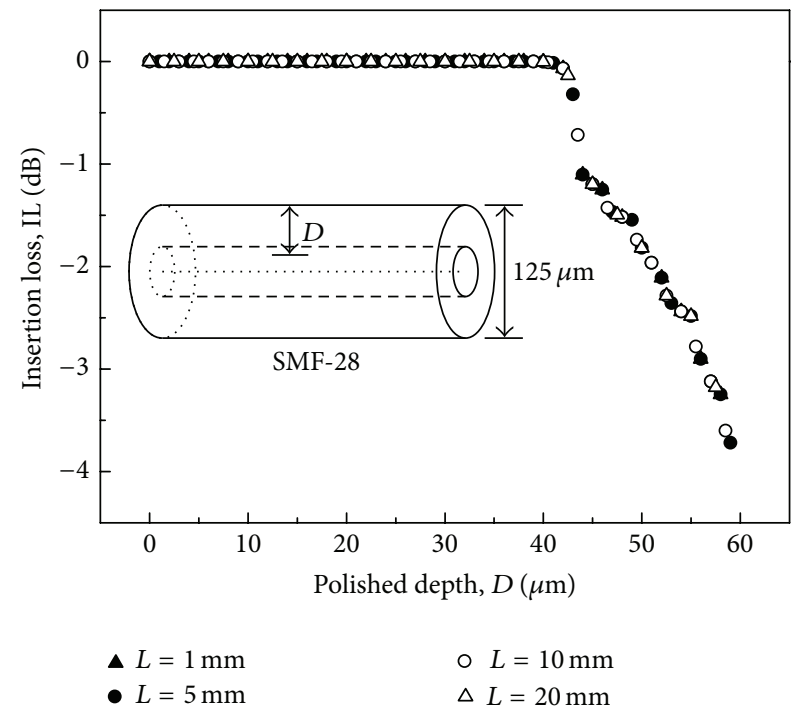

FIGURE 2: The simulated result of insertion loss IL versus the polished depth $D$ with the polished length $L=1,5,10$, and $20 \mathrm{~mm}$.

polished geometry and the insertion loss (i.e., $\mathrm{IL}=\mathrm{IL}(L$, $D)$ ), the simulated result is shown in Figure 2. It shows that the dominating fabrication parameter is the polished depths rather than the lengths. In the following experiments we chose the polished lengths $L$ of $5 \mathrm{~mm}$ and $10 \mathrm{~mm}$ for comparison.

A process for making the nanographene-based SAs was also developed. Graphitic plates with average thickness of $12 \mathrm{~nm}$, lateral dimension of $4.5 \mu \mathrm{m}$, and specific surface 


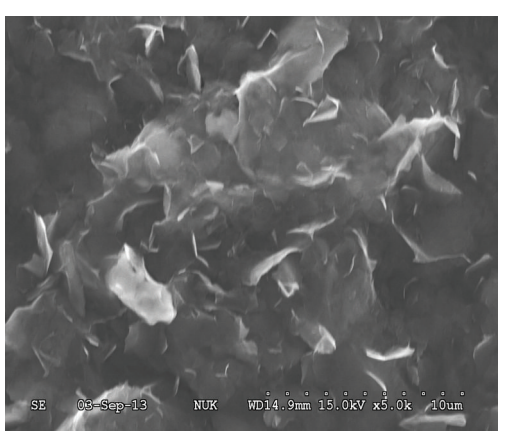

(a)

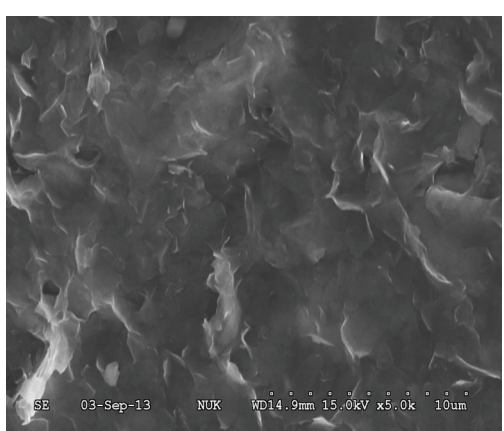

(b)

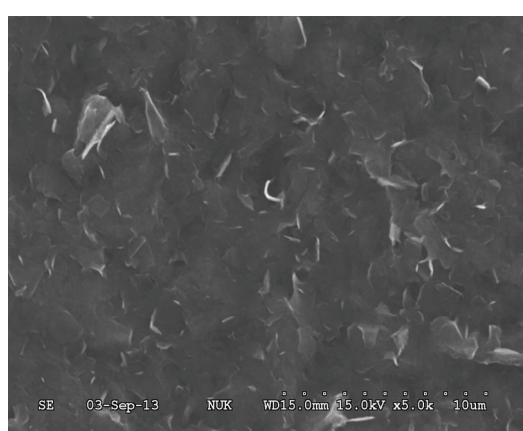

(c)

Figure 3: The SEM images of the mica-dispersed graphene-based SAs for different concentrations of (a) $1 \mathrm{wt} \%$, (b) $2 \mathrm{wt} \%$, and (c) $3 \mathrm{wt} \%$.

area of $80 \mathrm{~m}^{2} / \mathrm{g}$ were supplied by UP Co. (USA). Since the pristine graphitic plates tend to self-aggregate, it is difficult for solvating in water or organic solvents. The self-aggregation and plate-to-plate stacking are mainly caused by van der Waals force attraction. The selected layered silicate clays, the fluorinated mica (mica), were used as the dispersant to deaggregate graphene [20]. The procedures of mixing graphene and mica in water rendered the fine dispersion owing to the mutual interactions in their primary units. In [21], it was found that graphene can be well dispersed by the presence of mica and the physical mixture became readily dispersible in water. Graphenes of $0.1,0.2$, and $0.3 \mathrm{~g}$ with mica of $0.3,0.6$, and $0.9 \mathrm{~g}$ were ground adequately in an agate mortar and pestle, respectively. The mixture was then dispersed in $10 \mathrm{~g}$ of deionized water and agitated by ultrasonic treatment operated on a BRANSON 5510RDTH in a water bath for 2 hours. The precursor solution of homogenous mica-graphene dispersion was obtained. By using a simple solution-drop process, the graphene-based nanocomposite film was made after being dried thoroughly at ambient temperature. The concentrations of our graphenebased SA film were 1, 2, and $3 \mathrm{wt} \%$ representing the weight ratios of graphene to deionized water. Figure 3 shows the SEM images of the mica-dispersed graphene-based SAs for three different concentrations. We found that the sample of $3 \mathrm{wt} \%$ gave the better surface uniformity and it was used for the following experiments.

\section{Results and Discussion}

3.1. Optical Properties. The linear absorption spectrum of $3 \mathrm{wt} \%$ mica-dispersed graphene-based SA films examined by a UV-VIS-NIR spectrophotometer is shown in Figure 4. The trace shows the smooth absorption feature from 400 to $2000 \mathrm{~nm}$ due to its zero-gap linear band structure, as theoretically expected [11, 12]. It is different from the carbon nanotube that has specific absorption peaks originated from the energy band gap.

The optical nonlinearity of graphene-based SAs can be characterized by the intensity-dependent absorption coefficient as $\alpha(I, \lambda)=\alpha_{0}(\lambda) /\left(1+I / I_{s}\right)+\alpha_{\text {ns }}$, where $\alpha_{0}$ is the linear absorption coefficient, $I_{s}$ is the saturation intensity of the graphene-based SAs, and $\alpha_{\mathrm{ns}}$ is the nonsaturable

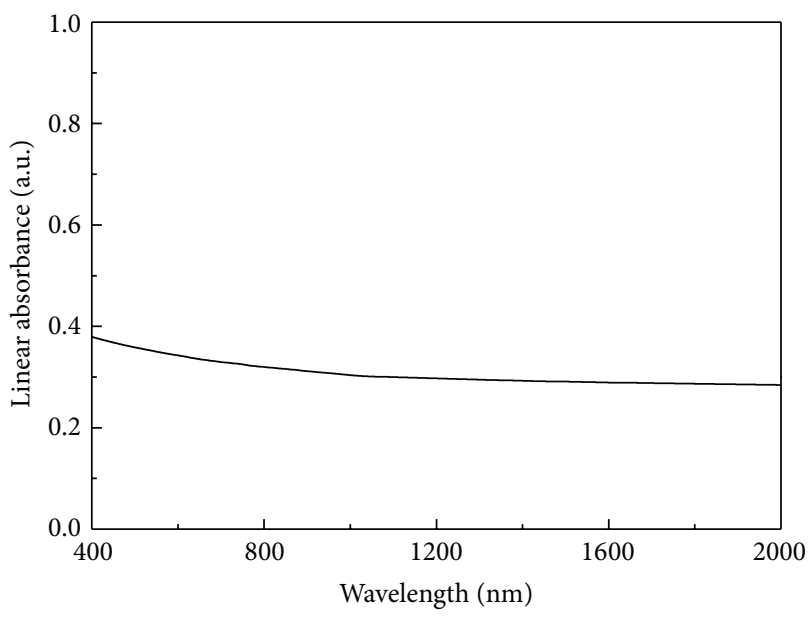

FIGURE 4: The linear absorption spectrum of $3 \mathrm{wt} \%$ mica-dispersed graphene-based SA films.

loss contributed from scattering of mica and graphene. The nonlinear transmission characteristics of graphene-deposited side-polished fiber devices were measured using a pulse laser that operated at the central wavelength of $1554.97 \mathrm{~nm}$ with a repetition rate of $25.1 \mathrm{MHz}$ and pulse duration of $383 \mathrm{fs}$. The measurement setup is depicted in Figure 5. The tested samples of insertion losses of $1 \sim 3 \mathrm{~dB}$ for both polished lengths of $5 \mathrm{~mm}$ and $10 \mathrm{~mm}$ were measured. The modulation depth (MD) is related to the coupling strength between the graphene-based SAs and the optical pulse. Therefore, MD depends on the polished depth. Figure 6 shows the dependence of MD on the polished depths and the highest MD occurred around $1.5 \mathrm{~dB}$ for both polished lengths. The MDs of $\mathrm{IL}=1.5 \mathrm{~dB}$, $L=5 \mathrm{~mm}$ and $\mathrm{IL}=1.68 \mathrm{~dB}, L=10 \mathrm{~mm}$ were $0.8 \%$ and $1.2 \%$, respectively. The nonlinear transmissions of these two samples are shown in Figure 7. Although the sample of the $\mathrm{IL}=1.68 \mathrm{~dB}, L=10 \mathrm{~mm}$ had the slightly higher $\mathrm{MD}$, it had larger linear nonsaturable losses of $65 \%$. The results showed that the higher MD only existed within certain polished depth region and MD dropped rapidly when polished more deeply. It might be because of the asymmetry of the mode field profile and severe scattering losses. Another observation of a sidepolished fiber device was sensitive to the optical pulse's state 


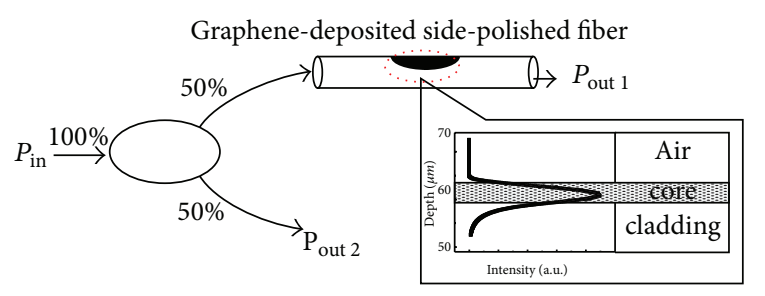

FIGURE 5: The setup of the nonlinear transmission measurement.

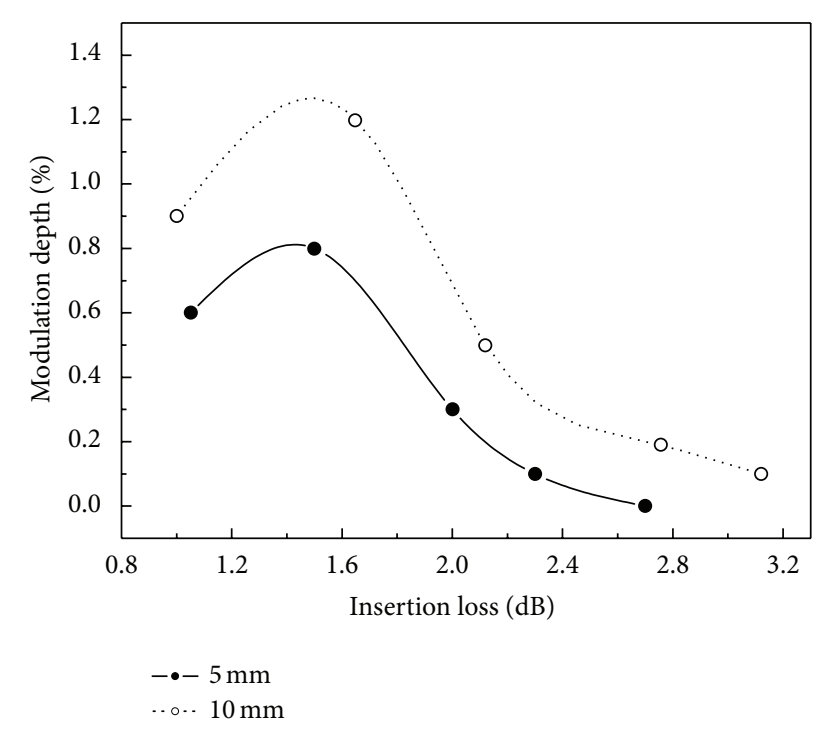

FIgURE 6: The modulation depths versus the insertion losses.

of polarization (SOP). The polarization dependent loss (PDL) of a side-polished fiber was measured about $0.6 \mathrm{~dB}$ and it was enhanced to $\sim 7.1 \mathrm{~dB}$ with the dispersed-graphene deposition.

3.2. Laser Performance. Figure 8 depicts our all-fiber passively mode-locked ring laser system incorporating a micadispersed graphene-deposited side-polished fiber device. An $85 \mathrm{~cm}$ long erbium-doped fiber (EDF) was used as a gain medium. It was pumped by a $980 \mathrm{~nm}$ laser diode via a wavelength division multiplexer (WDM). An isolator ensured the unidirectional operation. A polarization controller (PC) in this setup was a key element since our designed side-polished fiber device is sensitive to the state of polarization of the optical pulse. It was utilized to optimize mode locking. Total cavity length was $11.7 \mathrm{~m}$. The $30 \%$ of the intracavity power was tapped out by an output coupler, connecting to a power meter, an autocorrelator, an oscilloscope, and an optical spectrum analyzer to observe the power, the temporal pulse trace, the pulse train, and the optical spectrum, respectively. The remaining $70 \%$ of the optical power was fed back into the system. To clarify the source of mode locking, we verified and excluded the contribution from nonlinear polarization rotation (NPR) [22] and confirmed that the MLFL output of our cavity configuration was mainly contributed from the graphene-based SAs.

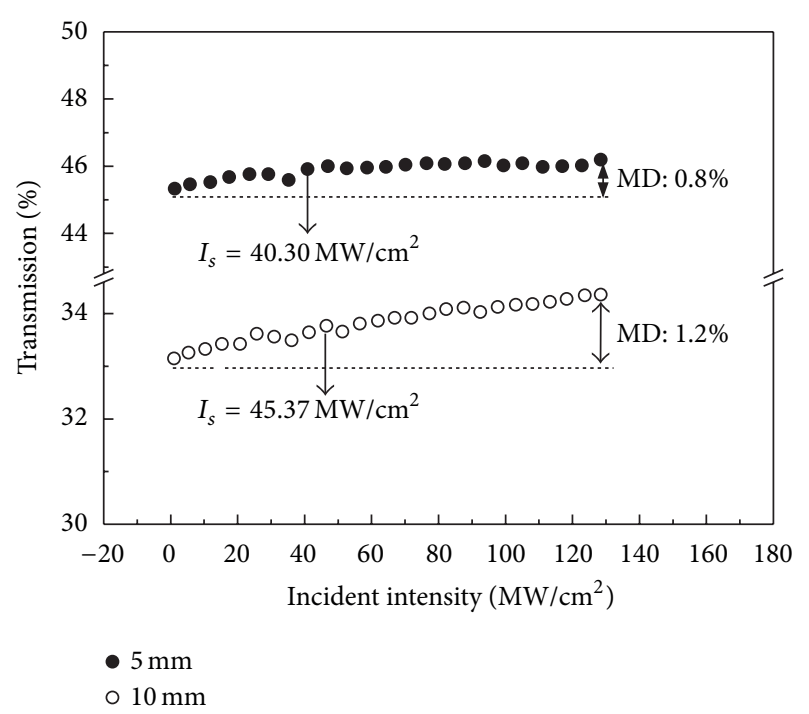

FIgURE 7: The nonlinear transmissions of tested samples of IL = $1.5 \mathrm{~dB}, L=5 \mathrm{~mm}$ and IL $=1.68 \mathrm{~dB}, L=10 \mathrm{~mm}$.

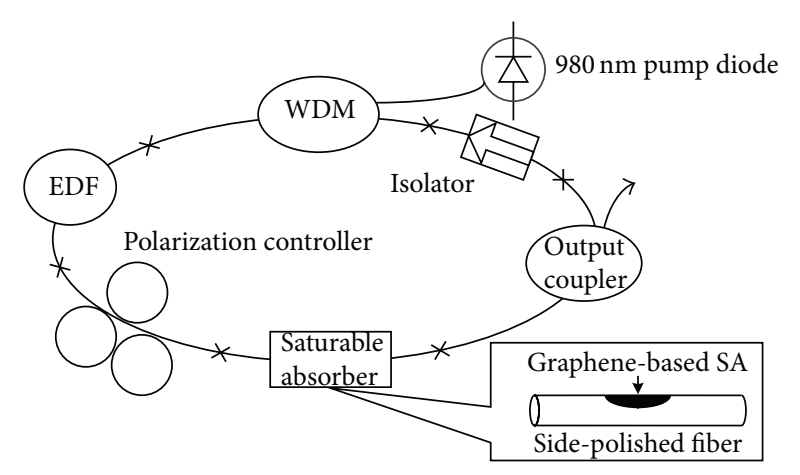

Figure 8: The configuration of our all-fiber passively mode-locked ring laser system.

All of the prepared samples have been tested and used as saturable absorbers for laser mode locking. We found that not all of them could be used as effective mode-locked SA elements. For those MDs which were smaller than $0.6 \%$ the nonlinear modulation was too weak to maintain laser mode locking. The better performance of a MLFL corresponded to the larger MD of $0.8 \sim 1.2 \%$ in our laser system. Figure 9 shows the dependence of $3 \mathrm{~dB}$ bandwidth on the polished depths which is indicated by the insertion loss. The optimized optical spectrum and the temporal pulse trace of IL $=1.5 \mathrm{~dB}, L=$ $5 \mathrm{~mm}$ and $\mathrm{IL}=1.68 \mathrm{~dB}, L=10 \mathrm{~mm}$ are shown in Figure 10 . Both pulse trains observed from the oscilloscope had the repetition rate of $16.7 \mathrm{MHz}$. A transform-limited pulse of $\operatorname{sech}^{2}$ is assumed to estimate the pulse width. The operated range of fundamental mode locking was very wide starting from 100 to $360 \mathrm{~mA}$ and the $3 \mathrm{~dB}$ bandwidth increased with the larger pumping current. The comparison of the passively MLFL optimized performance of two polished lengths is shown in Table 1. The sample of $10 \mathrm{~mm}$ polished length exhibited slightly shorter pulse width. It was also found that the different order of harmonic mode locking could be 
TABLE 1: Laser performance of graphene-deposited side-polished fibers.

\begin{tabular}{lccccc}
\hline Polished length, $L(\mathrm{~mm})$ & Insertion loss, IL $(\mathrm{dB})$ & $3 \mathrm{~dB}$ bandwidth $(\mathrm{nm})$ & Pulse width $(\mathrm{fs})$ & TBP & Pulse energy $(\mathrm{nJ})$ \\
\hline 5 & 1.50 & 5.0 & 583 & 0.357 & 0.23 \\
10 & 1.68 & 5.4 & 523 & 0.347 & 0.18 \\
\hline
\end{tabular}

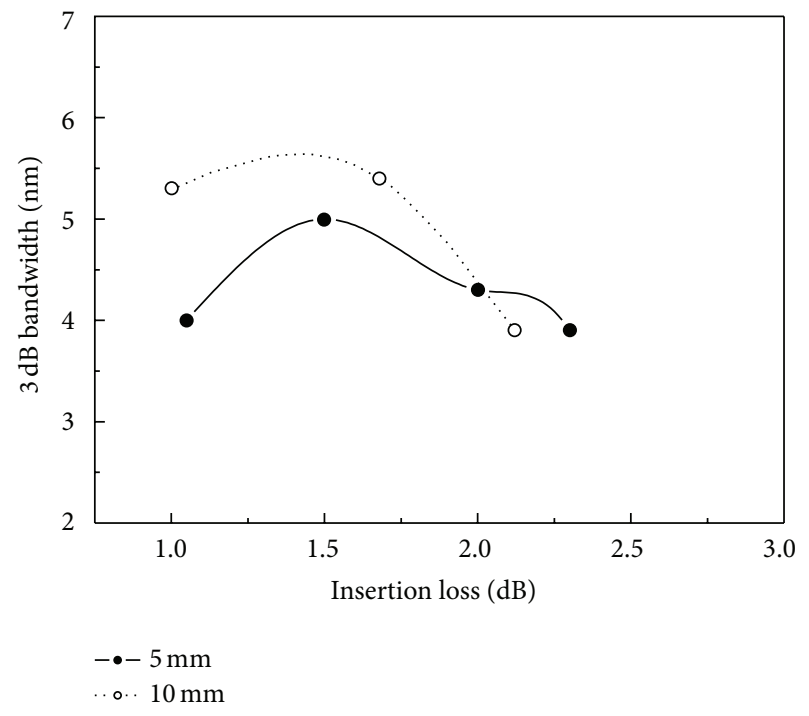

Figure 9: The $3 \mathrm{~dB}$ bandwidth versus the insertion losses.

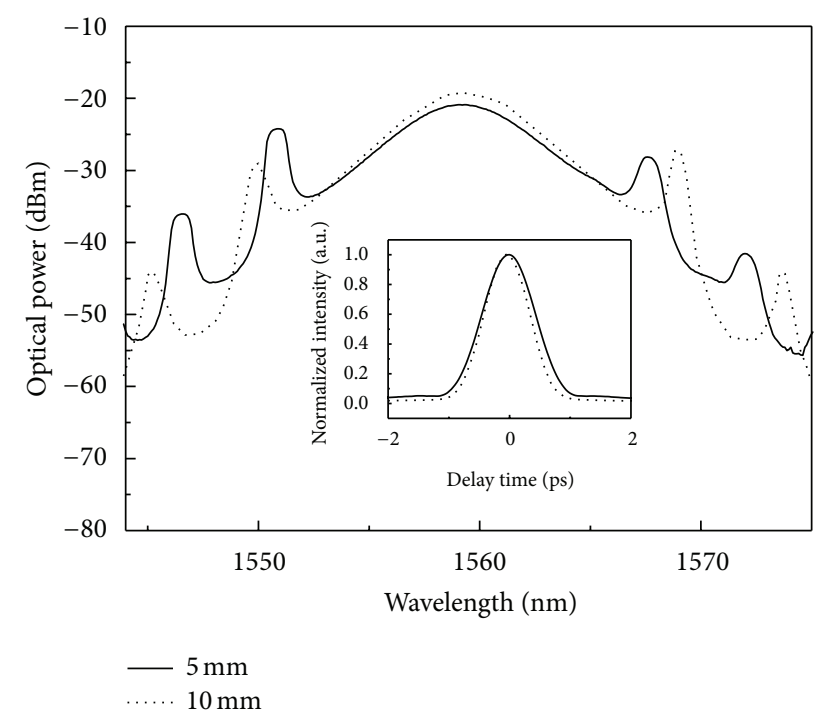

FIGURE 10: The optimized optical spectrum and the temporal pulse trace for samples of IL $=1.5 \mathrm{~dB}, L=5 \mathrm{~mm}$ and $\mathrm{IL}=1.68 \mathrm{~dB}, L=$ $10 \mathrm{~mm}$.

easily tuned by adjusting the polarization controller without changing the pumping power. The 16th harmonic mode locking was observed in our laser system.

\section{Conclusion}

The optical nonlinear properties of mica-dispersed graphenedeposited side-polished fiber devices with the different polished lengths and polished depths indicated by the insertion losses were investigated. The results were found that the higher MD only existed within certain polished depth region, and MD was slightly enhanced as the polished length increased. The insertion loss around $1.5 \mathrm{~dB}$ for both polished lengths showed the highest MD of $0.8 \%$ and $1.2 \%$. A MLFL employing the nanographene-based SA side-polished fiber was presented. For that MD which was smaller than $0.6 \%$, the nonlinear modulation was too weak to maintain mode locking. The better stable performance of a MLFL corresponded to the larger MD of $0.8 \sim 1.2 \%$ in our laser system. A stable MLFL employing the IL $=1.68 \mathrm{~dB}, L=10 \mathrm{~mm}$ sidepolished fiber device had the optimized performance with a pulse width of $523 \mathrm{fs}$, a $3 \mathrm{~dB}$ bandwidth of $5.4 \mathrm{~nm}$, a timebandwidth product of 0.347 , a repetition rate of $16.7 \mathrm{MHz}$, and pulse energy of $0.18 \mathrm{~nJ}$. This study demonstrates that the femtosecond pulse could be easily achieved by evanescent field coupling through graphene-deposited side-polished fiber devices in the laser cavity. The polished depth is the key fabrication geometric parameter affecting the overall optical performance.

\section{Conflict of Interests}

The authors declare that there is no conflict of interests regarding the publication of this paper.

\section{Acknowledgments}

The authors would like to thank the National Science Council, Taiwan, for financially supporting this research under Contract NSC 101-2221-E-390-015. The authors also thank Professor Wood-Hi Cheng's Laboratory of National Sun YatSen University for the support of the instrument use.

\section{References}

[1] F. Dausinger, F. Lichtner, and H. Lubatschowski, Femtosecond Technology for Technical and Medical Applications, vol. 96 of Topics in Applied Physics, Springer, Berlin, Germany, 2004.

[2] U. Keller, "Recent developments in compact ultrafast lasers," Nature, vol. 424, no. 6950, pp. 831-838, 2003.

[3] E. G. Arthurs, D. J. Bradley, and A. G. Roddie, "Buildup of picosecond pulse generation in passively mode-locked rhodamine dye lasers," Applied Physics Letters, vol. 23, no. 2, pp. 88-89, 1973 .

[4] H. A. Haus, "Mode-locking of lasers," IEEE Journal on Selected Topics in Quantum Electronics, vol. 6, no. 6, pp. 1173-1185, 2000.

[5] H. A. Haus, "Theory of mode locking with a fast saturable absorber," Journal of Applied Physics, vol. 46, no. 7, pp. 30493058, 1975. 
[6] M. E. Fermann, "Ultrafast fiber oscillators," in Ultrafast Lasers: Technology and Applications, Marcel Dekker, New York, NY, USA, 2003.

[7] I. Hernandez-Romano, D. Mandridis, D. A. May-Arrioja, J. J. Sanchez-Mondragon, and P. J. Delfyett, "Mode-locked fiber laser using an SU8/SWCNT saturable absorber," Optics Letters, vol. 36, no. 11, pp. 2122-2124, 2011.

[8] T. Hasan, Z. Sun, F. Wang et al., "Nanotube-polymer composites for ultrafast photonics," Advanced Materials, vol. 21, no. 3839, pp. 3874-3899, 2009.

[9] S. Yamashita, "A tutorial on nonlinear photonic applications of carbon nanotube and graphene," Journal of Lightwave Technology, vol. 30, no. 4, pp. 427-447, 2012.

[10] S. Y. Set, H. Yaguchi, Y. Tanaka, and M. Jablonski, "Laser mode locking using a saturable absorber incorporating carbon nanotubes," Journal of Lightwave Technology, vol. 22, no. 1, pp. 51-56, 2004.

[11] A. K. Geim and K. S. Novoselov, "The rise of graphene," Nature Materials, vol. 6, no. 3, pp. 183-191, 2007.

[12] F. Bonaccorso, Z. Sun, T. Hasan, and A. C. Ferrari, "Graphene photonics and optoelectronics," Nature Photonics, vol. 4, no. 9, pp. 611-622, 2010.

[13] Q. Bao, H. Zhang, Y. Wang et al., "Atomic-layer craphene as a saturable absorber for ultrafast pulsed lasers," Advanced Functional Materials, vol. 19, no. 19, pp. 3077-3083, 2009.

[14] Z. Sun, T. Hasan, F. Torrisi et al., "Graphene mode-locked ultrafast laser," ACS Nano, vol. 4, no. 2, pp. 803-810, 2010.

[15] P. L. Huang, S.-C. Lin, C.-Y. Yeh et al., "Stable mode-locked fiber laser based on CVD fabricated graphene saturable absorber," Optics Express, vol. 20, no. 3, pp. 2460-2465, 2012.

[16] P. L. Huang, H. H. Kuo, R. X. Dong et al., "Performance of graphene mediated saturable absorber on stable mode-locked fiber lasers employing different nano-dispersants," Journal of Lightwave Technology, vol. 30, no. 21, pp. 3413-3419, 2012.

[17] Y.-W. Song, S. Yamashita, C. S. Goh, and S. Y. Set, "Carbon nanotube mode lockers with enhanced nonlinearity via evanescent field interaction in D-shaped fibers," Optics Letters, vol. 32, no. 2, pp. 148-150, 2007.

[18] Y.-W. Song, S.-Y. Jang, W.-S. Han, and M.-K. Bae, "Graphene mode-lockers for fiber lasers functioned with evanescent field interaction," Applied Physics Letters, vol. 96, no. 5, Article ID 051122, 2010.

[19] Y.-W. Song, K. Morimune, S. Y. Set, and S. Yamashita, "Polarization insensitive all-fiber mode-lockers functioned by carbon nanotubes deposited onto tapered fibers," Applied Physics Letters, vol. 90, no. 2, Article ID 021101, 2007.

[20] Y.-F. Lan and J.-J. Lin, "Observation of carbon nanotube and clay micellelike microstructures with dual dispersion property," The Journal of Physical Chemistry A, vol. 113, no. 30, pp. 86548659, 2009.

[21] H. H. Kuo, P. L. Huang, C. Y. Yeh, and W. H. Cheng, "Few-layer graphene-based saturable absorbers employing mica dispersant for stable mode-locked fiber lasers," IEEE Photonics Technology Letters, vol. 25, no. 7, pp. 633-636, 2013.

[22] G. P. Agrawal, Application of Nonlinear Fiber Optics, Academic Press, New York, NY, USA, 2nd edition, 2008. 

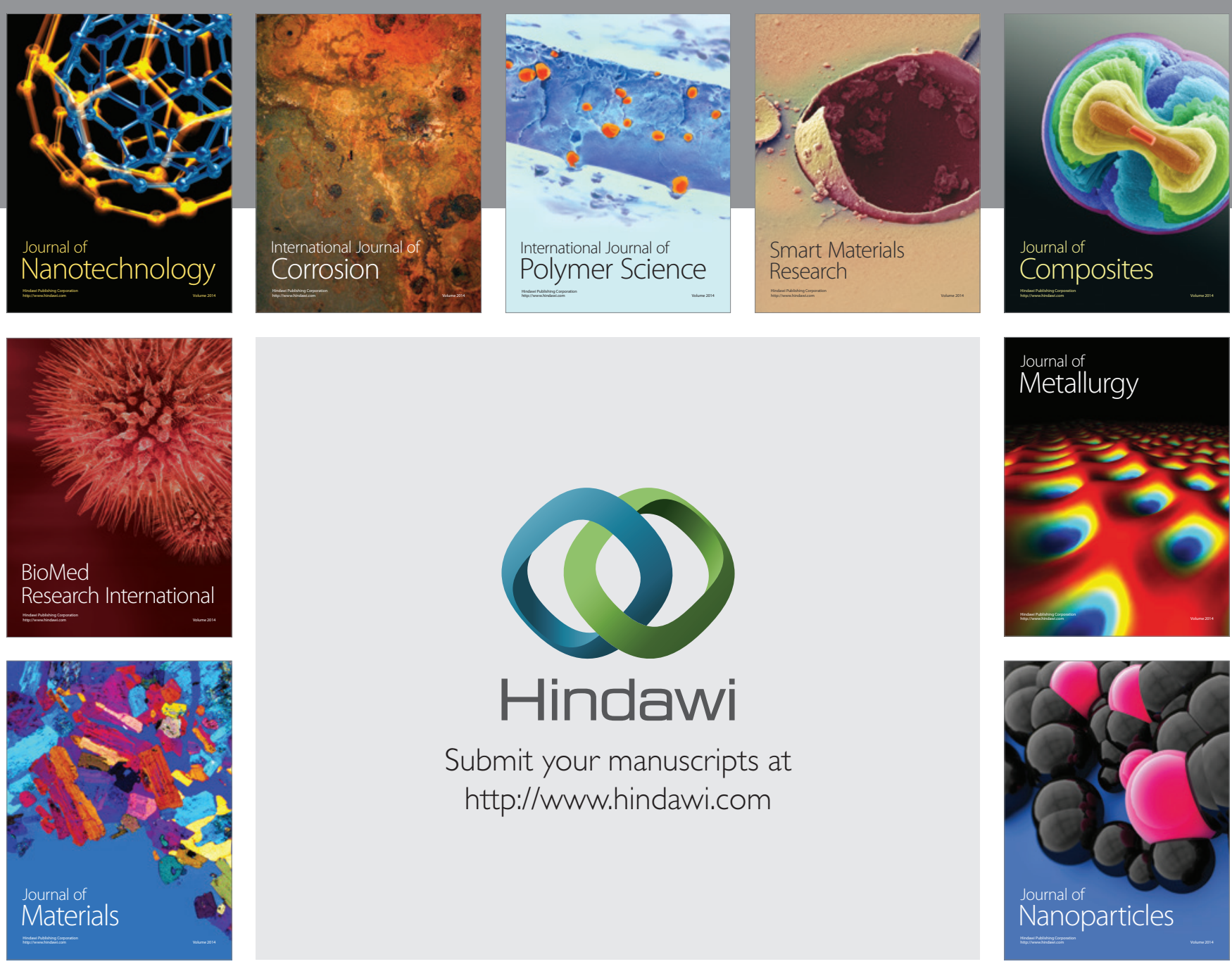

Submit your manuscripts at http://www.hindawi.com
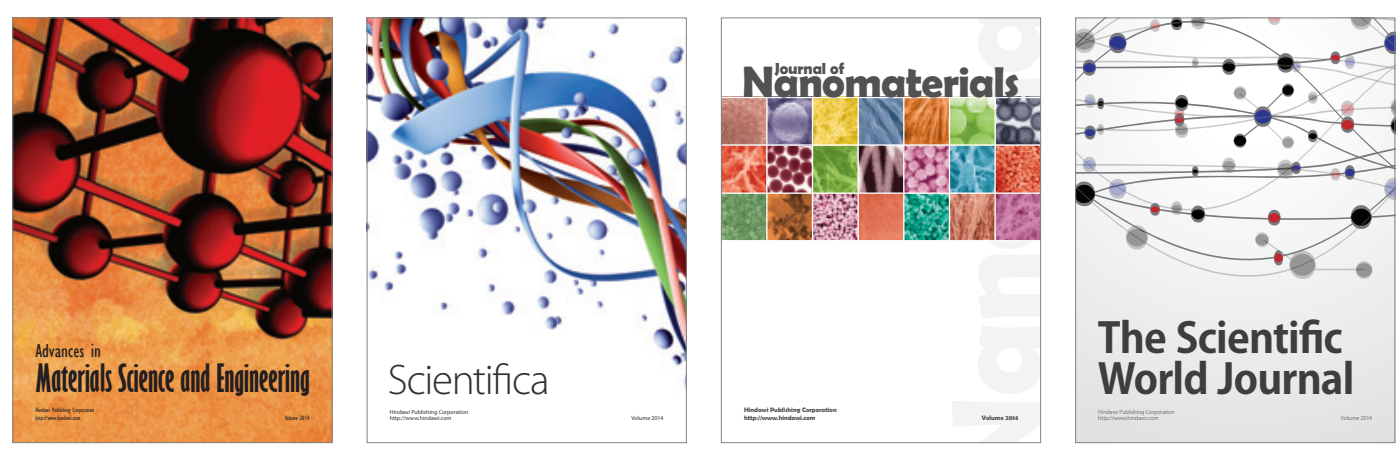

\section{The Scientific World Journal}
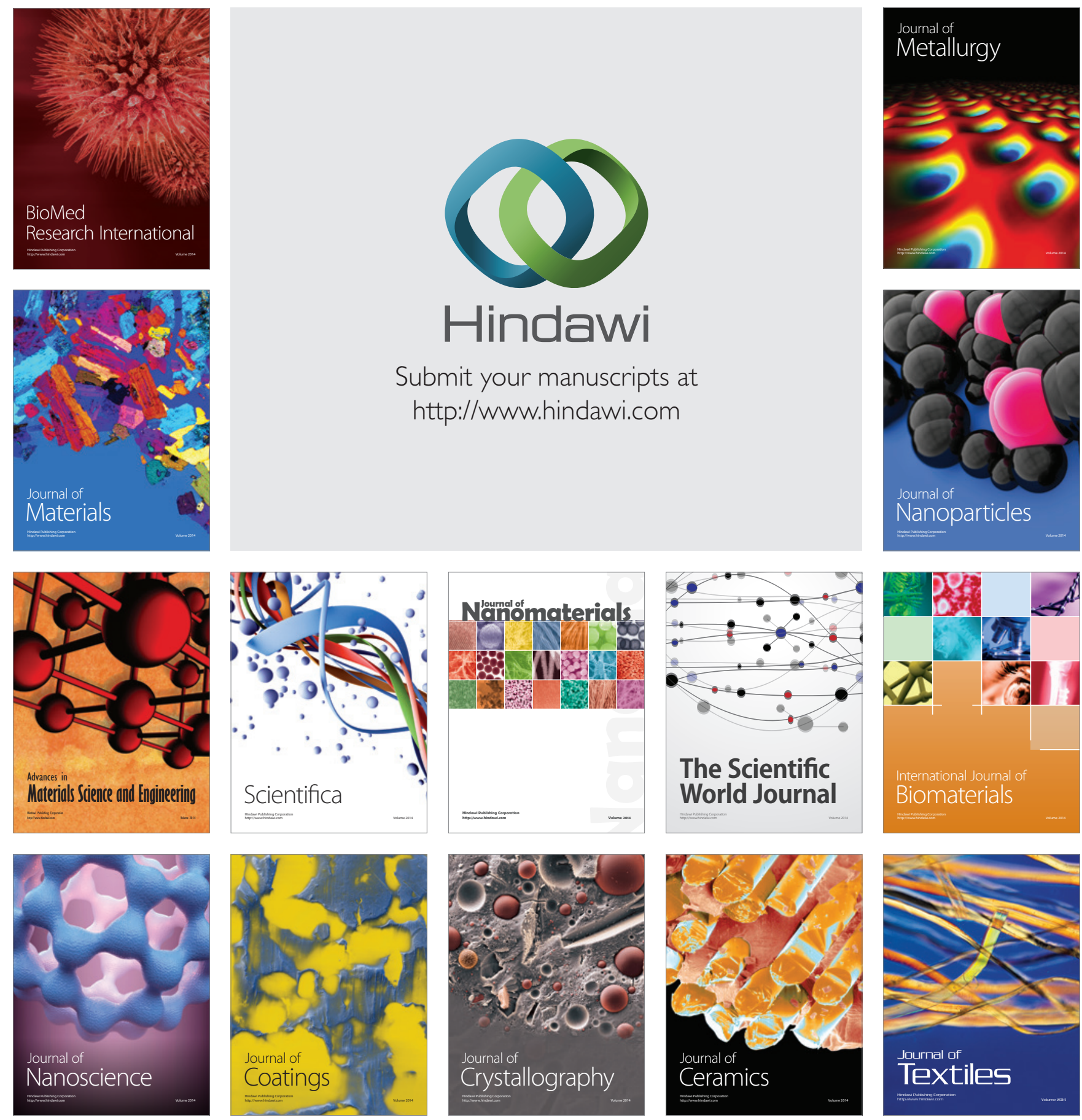